\title{
Romatoid Artritte Göz Bulgularının Değerlendirilmesi
}

\author{
Results Evaluation of the Eye in Rheumatoid Arthritis
}

\author{
Rukiye YAZICI ${ }^{1}$, Turgut KÜLTÜR ${ }^{2}$, AlperYAZICI ${ }^{3}$ \\ ${ }^{I}$ Balıkesir Devlet Hastanesi Fizik Tedavi ve Rehabilitasyon Kliniği, BALIKESIR \\ ${ }^{2}$ Kazan Devlet Hastanesi Fizik Tedavi ve Rehabilitasyon Kliniği, ANKARA \\ ${ }^{3}$ Balıkesir Üniversitesi Göz Hastalıkları Anabilim Dalı, BALIKESIR
}

\begin{abstract}
ÖZET
Romatoid artritli hastalarda göz sıklıkla tutulabilmektedir. Gerek hastalı̆̆ın seyrindeki inflamasyon, gerekse de kullanılan ilaçlara bağlı olarak göz etkilenmektedir. Genellikle hastalığın ağır seyrettiği olgularda ve ileri yaş kadın hastalarda göz tutulumu daha s1k görülmektedir. Artritin ortalama süresi ve seropozitivitenin ortalama süresiyle oküler komplikasyon varlığı arasında belirgin korelasyon söz konusudur. Romatoid artrit hastalarının bir kısmında hastalığın tedavisi göz bulgularının düzelmesi için yeterli olabilmesine rağmen bir grup hastada ise gözdeki hastalığın ilave ilaçlarla ayrıca tedavisi gerekli olabilmektedir. $\mathrm{Bu}$ makalede romatoid artritte görülen göz bulguları, oluşum mekanizmaları, klinikleri ve tedavi protokollerinin değerlendirilmesi amaçlanmıştır.
\end{abstract}

Keywords: Romatoid Artrit, göz tutulumu,komplikasyonlar

\begin{abstract}
Ocular involvement is frequent in patient with rheumatoid arthritis. Eyes are affected whether by the inflammation in disease progress or by the medications used. Ocular involvement is more frequent in patients with severe disease or elderly female patients. There is a significant correlation between the ocular complications and mean disease period and seropositivity period. For some rheumatoid arthritis patients systemic teatment of disease is enough for disappearance of ocular symptoms but for the others specific medications are needed for ocular symptoms. Aim of this article is the discussing ocular signs and pathophysiology in rheumatoid arthritis and their treatment modalities
\end{abstract}

Anahtar Kelimeler: Rheumatoid Arthritis, ocular involvement,complications

\section{GİRIŞ}

Romatoid artrit (RA) eklemlerde ağrı, şişlik, tutukluk ve fonksiyon kaybına neden olabilen ve iltihabi hastalıklar içerisinde en s1k görülen kronik bir durumdur. Kadınlarda 3 kat daha sık görülmekte olup ve sıklığı 20-50 yaşları arasında artış göstermektedir (1). Hastalık kronik hastalık anemisi, romatoid nodüller, akciğerde plevral effüzyon ve göz bulguları gibi eklem dişı tutulumlar ile de seyredebilmektedir. $\mathrm{Bu}$ makalede romatoid artritte görülen göz bulguları, oluşum mekanizmaları, klinikleri ve tedavi protokollerinin değerlendirilmesi amaçlanmıştır.

\section{Romatoid Artritte Göz Tutulumu}

RA'de göz tutulumu sık görülür. Gerek hastalığın seyrindeki inflamasyon, gerekse de kullanılan ilaçlara bağlı olarak göz etkilenmektedir. Genellikle hastalığı ağır seyredenlerde ve ileri yaş kadın hastalarda göz tutulumu daha sık gözlenir. Artritin ortalama süresi ve seropozitivitenin ortalama süresiyle oküler komplikasyonlar arasında belirgin korelasyon olduğu bildirilmektedir (2). Erişkin RA'lı hastalarda \%22.4 oranında oküler komplikasyon görülmektedir. 
En s1k olarak keratokonjunktivitis sikka (KKS) görülürken diğer göz tutulumları arasında ise episkleritis, skleritis, korneanın marjinal incelmesi, iridosiklit ve periferal vaskülarizasyonlu stromal ve korneal opasite oluşumları yer almaktadır.

\section{Keratokonjuktivitis sikka}

Romatoid artritin en s1k saptanan göz bulgusudur. Gözyaşının yapısında musin, aköz ve lipid tabakalar mevcuttur. Kuru göz semptomları bu 3 tabakada oluşan yetmezliklerden dolayı ortaya çıkmaktadır. Müsin tabaka konjonktival goblet hücreleri tarafindan oluşturulur. Aköz tabaka ise lakrimal bez ve aksesuar lakrimal bezler tarafindan salgılanır. En yüzeyde bulunan lipit tabaka ise meibomius bezleri tarafindan salgılanır. RA ve diğer bağ dokusu hastalıklarında ekzokrin bez olan lakrimal bezin lenfositik infiltrasyonu ve otoimmun yıkımı sonucunda genellikle aköz gözyaşı yetmezliği söz konusudur (1). Hastalarda lakrimal bez yardımcı T lenfositler ve IgG sekrete eden B lenfositlerce infiltre edilir ve sekretuvar epitelyumda meydana gelen atrofi sonucunda fibroz bağ dokusu oluşur. $\mathrm{Bu}$ durumda gözyaşı üretiminin azalması gözyaşı osmolaritesinde artışa sebep olur. Oküler yüzeydeki osmolaritenin artışı enflamatuvar sitokinlerin artışı ile beraber oküler yüzey inflamasyonu ile sonuçlanır. Oküler yüzey enflamasyonu da konjonktivadaki yardımeı lakrimal bezler ve goblet hücrelerinin hasarına sebep olmakta ve göz kuruluğu daha da artmaktadır. Kuru gözde görülen oküler yüzey inflamasyonu, oküler yüzeyde ve gözyaşında inflamatuar sitokinlerin, kemokinlerin, adezyon moleküllerinin ve matriks metalloproteinazların (MMP) saptanmasiyla anlaşılmıştır. Artmış MMP ekspresyonu ve aktivasyonu kornea epitel bazal membranı ve kornea epitel bariyer fonksiyonunu sağlayan proteinlerin lizisine neden olarak kuru göz şikâyetlerini ve bulgularını artırmaktadır. İlerleyici lenfosit infiltrasyonu, salınan sitokinlerle birlikte epitelyal hasara neden olarak inflamasyonu ve apoptozisi tetikler. Kuru göz hastalarında proapoptotik belirleyiciler konjunktiva epitelinde artmış olarak tespit edilmiştir (3). KKS'nin başlangıç döneminde; gözlerde kuruluk, yabancı cisim ve batma hissi, kaşıntı, yanma, fotofobi, görmede bulanıklık, kızarıklık gibi semptomlar rapor edilmiştir (4). Bu durum şiddetli ise ve tedavi edilmezse görme kaybı ya da görme bozukluğu ile sonuçlanan göz hasarına sebep olabilir. Başlangıçta kuru göz oküler yüzeyde abrazyon, ileri durumlarda da epitelde squamoz metaplazi ve goblet hücre kaybına sebep olur. Ciddi vakalarda korneal kalınlaşma, korneal erozyon, punktat kerotopati, korneal skar, korneal ülser, korneal incelme, korneal perforasyon gözlenebilir. $\mathrm{Bu}$ komplikasyonlardan dolayı tanının erken konulup tedavi başlanması morbidite oranının azaltılması için önem arzeder (5). Schimer testi gözyaşının miktarının ölçülmesini sağlayan uygulanması kolay bir tarama testidir. $\mathrm{Bu}$ testte $35 \mathrm{~mm}$ uzunluğunda ve $5 \mathrm{~mm}$ genişliğinde emici Whatmann filtre kâğıtlarından yararlanılır. Topikal anestezik damlatılarak bazal gözyaşı üretimi, anestezisiz ise hem bazal hem refleks gözyaşı üretimi ölçülür. Whatmann filtre kâğıdı ucu kıvrılarak alt kapak dış $1 / 3$ kısmına yerleştirilir ve 5 mm'den az/ anestezisiz ölçümde ise $10 \mathrm{~mm}$ 'den az olması tanı koydurucudur (6).

Oküler Boyama Testleri: KKS'nin teşhisinde fluorescein sodyum, rose bengal ve lizamin yeşili gibi oküler yüzey boyaları rutin olarak kullanılmaktadır. Gözyaşının azalması ve içeriğinin bozulması ile kornea ve konjuktiva oküler yüzey hücrelerindeki ölü hücrelerin boyanması bu vital boyalar değerlendirilebilir (7).

Gözyaşı kırılma zamanının (GKZ) ölçülmesi gözyaşının kalitesi ve kararlılığındaki bozulmayı gösterir. Bu test aköz gözyaşı yetersizliği veya gözyaşı kurumasından ileri gelen KKS'li ve meibomian bez disfonksiyonlu bireylerde tanısal öneme sahiptir. Göze fluorescein uygulanmasını takiben iki tam göz kırpma arasında oküler yüzeyde noktasal kurulukların ilk tespit edildiği zaman olarak bilinmektedir. Kırılma alanları, 
slit-lamp biyomikroskop altında kobalt mavisi veya sarı filtre kullanılarak tespit edilir. GKZ' nin normal bireylerde ortalama 27 saniye, KKS'li hastalarda ise ortalama 5 saniye olduğu bildirilmiştir (7).

Gözyaşı Osmolaritesi Testleri, KKS'nin tüm formlarında oküler yüzey hasarının belirlenmesinde kullanılan en önemli parametredir. Günümüzde kuru göz tanısında ve hastalık ciddiyetini belirlemede altın standart tanı yöntemi olarak kabul edilmektedir. Normal bireylerde gözyaşı osmolaritesinin 300-310, KKS'li insanlarda ise bu değerlerin 316 ile 360 $\mathrm{mOsm} / \mathrm{kg}$ arasında değiştiği rapor edilmiştir (8) .

Gözyaşı Tabakası Durağanlığı Değerlendirme Sistemi ve Fonksiyonel Görme Keskinliği Ölçeği gibi bilgisayarlı gözyaşı kalitesi ve görme potansiyeli ölçümü yapan cihazların, romatolojik hastalıklara bağlı KKS'nın erken tanısında önemli rol oynayabileceği ile ilgili tartışmalar halen devam etmektedir (9). İnvaziv olmayan gözyaşı menisküs yüksekliği ve kurvatürü ölçümlerinin romatolojik hastalıklara bağlı KKS'nin şiddetinin ve tedaviye yanıtının değerlendirilmesinde önem taşıyabileceği bildirilmiştir (10) .

KKS hastalığının birincil tedavisinde suni gözyaşları kullanılmaktadır. Prezervanların da oküler yüzeyde toksisite ve enflamasyona yol açabileceği akılda tutulmalı ve mümkünse prezervansız tek kullanımlık damlalar tercih edilmelidir. Tedavi sonrasında kornea topografisindeki yüzey düzensizliği indisleri düzelmekte ve hastaların görme potansiyelleri de iyileşmektedir.

Non-Steroid Anti İnflamatuar İlaç (NSAIII) Tedavi: Oküler inflamasyonun kontrol altına alınmasında etkilidir. NSAIII'lar, siklooksijenaz enzimlerini bloke ederek prostaglandin ve diğer maddelerin sentezini inhibe ederek rol almaktadır (11). $\mathrm{Bu}$ amaçla bromfenak, diklofenak, flurbiprofen, indometazin, ketorolak, nepafenak ve suprofen gibi ajanlar s1klıkla kullanılmaktadır. Lekhanont K. ve ark KKS üzerine nepafenak, ketorolak, bromfenak ve diklofenak gibi lokal NSAIII'ların etkilerini değerlendirmişlerdir. Tedavinin 2. haftasında nepafenak uygulanan olgularda korneal fluorescein boyanma alanlarında belirgin azalmalar gözlenirken; ketorolak, diklofenak ve bromfenak uygulananlarda ise tedavinin üzerinden 4 hafta geçmesine rağmen boyama alanlarında kısmi bir azalmanın olduğu bildirmişlerdir (12).

Kortikosteroid (KS) tedavi: KS inflamatuar süreci önlemede önemli rol oynar. Metilprednisolon, deksametazon, fluorometanol ve loteprednol, etabonat gibi kortikosteroid grubu antiinflamatuar ajanların KKS vakalarında etkin sonuçlar verdiği bildirilmişstir. KKS vakalarının \% 1'lik metilprednisolonla yapılan tedavisinde 2 hafta sonra hastalığın şiddetinde \%43-57 arasında değişen bir iyileşme sağlandığı ve olgularda fluorescein boyanma alanlarının azaldığı rapor edilmiştir (13).

İmmunsupresif tedavi: $\mathrm{T}$ lenfosit çoğalmasını ve aktive olmuş yardımcı $\mathrm{T}$ hücrelerinden IL-2 üretimini özel olarak inhibe eden bir immün düzenleyici olan Siklosporin A monoterapisi ya da kombine tedavinin bir parçası olarak kullanılmaktadır. Topikal 0,05\% siklosporin, Amerikan Gıda ve İlaç Dairesi (FDA) tarafından, 2003 yılında KKS tedavisi için onaylanmıştır (14). Gündüz ve arkadaşları, 1994 yılında yaptıkları çalışmada, KKS hastalarında zeytinyağı içinde \%2 siklosporin A’nın, gözyaşı kırılma zamanı ve rose bengal boyama skorlarında anlamlı düzelmeye neden olduğunu, Schirmer skorlarında ise anlamlı düzelme olmadığını saptamışlardır (15). Yapılan bir çalışmada orta dereceden şiddetliye kadar değişen $32 \mathrm{KKS}$ 'lı olguda lokal siklosporin A'nın etkilerinin araştırılmasında, tedavi sonunda lenfosit aktivasyon belirleyicilerinin sayısında önemli azalmaların olduğu bildirilmiştir. Vakalardan alınan konjunktival biyopsi örneklerinin değerlendirmesinde lokal siklosporin A'nın konjunktival goblet hücre sayısını arttırdığı, epitelyal hasarı azalttığ1 ve epitelyumun proliferatif aktivitesi üzerine olumlu etkisinin olduğu tespit edilmiştir (16).

KKS'nin diğer tedavi seçenekleri arasında otolog serum kullanılması ve punktum tıkaçları kullanımı da mevcuttur. Punktum tıkacı kullanılması, nazolakrimal 
kanaldan gözyaşı kaybını azalttığı için orta ve ciddi kuru göz hastalığının tedavisinde kullanılan önemli bir seçenektir (17). Pınarcı ve arkadaşları, ciddi kuru göz olgularında antiinflamatuar tedavi ve yerine koyma tedavisi yetersiz kaldığında gözyaşı kaybını önleyen punktum tıkaçlarının etkili ve kolay uygulanabilir bir yöntem olduğu vurgulamışlardır (18). Otolog serum uygulaması ilk KKS hastalarında 1984 yılında kullanılmış ve faydalı olduğu gösterilmiştir. Serum içerisinde bulunan epidermal growth factor (EGF), tümör growth factor beta ve A vitamininin epitelizasyonu hızlandırıcı özellikleri vardır. A vitamini, KKS hastalarında skuamöz metaplazi progresyonunu azaltması nedeni ile önemli rol oynamaktadır. Otolog serum uygulamasının ana endikasyonu, inatçı kornea epitel bozuklukları, punktat epitel erozyonları, filamenter keratit veya nörotrofik ülserler ile ortaya çıkan KKS'dır (19).

\section{Episklerit}

Gözde kızarıklık ve hafif rahatsızlık hissi oluşturan hafif bir durumdur. Basit ve nodüler tipte olabilen, genellikle benign ve yineleyici bir episkleral tutulum mevcuttur. Oftalmoloji kliniğine episkleritle başvuran hastaların \%5.6'sında RA tespit edilmiştir. Şiddetli ağrı gözlenmez. Episkleritin neden olduğu kızarıklık somon pembe olarak tarif edilir. Skleritte ise derin mor renk gözlenir. \%10'luk felinefrin damla ile episkleral damarlarda daralma ve beyazlaşma olur, fakat bu durum skleritte olmaz. Genellikle topikal steroid tedavisiyle semptomlar kontrol altına alınabilir ancak temel tedavide oral NSAIII kullanılmalıdır (20) .

\section{Sklerit}

Gözde ağrı görme bozukluğuna sebep olan gözün en dış kollajen tabakası skleranın inflamasyonu ile karakterize ciddi bir göz patolojisidir. Sklerit tanısı alan hastaların \%33'ünde RA saptanmıştır. RA'lı olgularda ise \%0.67 ile \%6.3'e varan oranlarda sklerit sıklığı rapor edilmiştir. Eroziv eklem tutulumu olan ve uzun süreli hastalık hikâyesi olan hastalarda daha sık gözlenmektedir. Skleritli hastaların klinik bulguları daha derin ve şiddetli olmaya meyillidir. Ayrıca hastalarda ilaveten fotofobi, segmental şekilde veya tüm ön sklerayı içine alan kırmızılık da mevcuttur (21). Sklerit 3 tipte görülmekte olup en sık görülen formu diffüz anterior sklerit; ikincisi nodüler sklerit ve üçüncüsü inflamasyon olmaksızın skleranın aşırı incelmesiyle karakterize, skleromalazi perforans olarak da adlandırılan nekrotizan sklerittir.

\section{Anterior sklerit}

Uykuyu bozacak kadar şiddetli göz ve baş ağrısı şikâyetleri mevcuttur. Fotofobi ve kızarıklık vardır fakat vizyon normaldir. Skleritin nadiren ağrı ve kızarıklık olmadan sklerada ilerleyici incelme yapabilen formu RA'da sık olarak gözlenir. $\mathrm{Bu}$ hastalarda skleranın incelmesi ile melanosit yüklü koroid tabaka görünür hale gelir ve mavi siyah sklera görünümü oluşur. Bu skleromalazi performans olarak bilinir ve daha çok yaşı bayanlarda görülür. Kırmızılığın yanı sıra episkleral koroid pleksusun tutulumu ile viyolese renk oluşur. Bazen sklera üzerinde hassas, firm, kırmızı bir nodül gözlenebilir. Mavi veya koyu kahverengi renk gözlenmesi skleral incelmenin göstergesidir. Gözde şiddetli ağrı ve palpasyonda hassasiyet mevcuttur. Slit-lamp biomikroskopla skleral ve episkleral ödem değerlendirilir (22). Episkleritten \%10'luk felinefrin damlatılarak anterior skeritteki kızarıklığın kalıcı olması ile ayırt edilebilir. Periferal kornea tutulumu ciddi bir hastalık göstergesidir. Korneal infitratlar ve korneal incelme ve ülserler gözlenebilir. Nekrotizan sklerit görmeyi ciddi olarak tehdit eden bir durumdur. Sklerada dilate olmuş damarların çeveresinde non perfuze kapiller alanların meydana getirdiği sarı soluk yama şeklinde alanlar gözlenir. İskemik sklerada nekroz ve incelme skleranın mavi renk almasına sebep olur (23) . 


\section{Posterior sklerit}

Posterior sklerada enflamasyon ve kalınlaşma vardır. Enflamasyon rektus kaslarının insersiyosuna uzanabilir. Hastaların yarısında ağrı mevcuttur ve üçte bir oranında anterior skleritle birliktelik gözlenir. Kasların inflamasyonuna bağlı göz hareketlerinde ağrı olabilir ve hafif pitozis bulunabilir. Bulanık görme yaygın olarak gözlenir ve genellikle Snellen görme keskinliği azalmıştır. Hastaların 1/5'inde fizik muayene tamamen normaldir. Ön segmentte inflamasyon bulguları gösterebilirler. Arka alan değerlendirmede optik sinirde şişlik gözlenebilir; fakat ışığa pupil yanıtı, renkli görme ve görme alanı değerlendirilmesi normaldir. Bu bulgu iskemik optik nöropati ve optik nöritin ayırıcı tanısının konulması açısından değerlidir. \%25 olguda eksudadif retina dekolmanı görülebilir. Diffüz daha sık olmak üzere, noduler posterior sklerit formunda da olabilir. Noduler tipte arka segmentte soluk solid kitle görünümü mevcuttur (24).

Tedavide amaç inflamasyonun kontrol altına alınmasıdır. $\mathrm{Bu}$ amaçla NSAİ̇, steroidler, immunsüpresanlar, biyolojik ajanlar kullanılmaktadır. RA'l1 olgularda topikal beklametazon tedavisine yanıt istenen seviyede değildir. Şiddetli skleritli olgularda siklosporin tedavisinin etkili olduğu gösterilmiştir, ancak yan etkileri açısından kullanımı sınırlıdır (25). Siklosporin tedavisine oral steroid eklenebilir ama skleritte yavaş yavaş düzelme olsa da etkinliği sınırlıdır (26). Hafif skleritli olgularda NSAIII tedavisi etkili olmaktadır, fakat lokal olarak kullanım etkili değildir. Yaygın ve nodüler anterior skleritte \%30-92 oranında tedaviye yanıt alınmaktadır (27).

Sistemik steroidler: Prednizonla (1 mg/kg/gün) yüksek dozlarda başlanılır. Çoğu sklerit steroid tedavisine cevap verir. Günde 7,5-10mg'dan daha yüksek dozlarda prednizonla nüks oluşan hastalarda ek immünosüpresif tedavi düşünülmelidir (28).

Smith ve arkadaşlarının etanersept kullanan 6 RA'lı hastada yaptıkları çalışmada 2 hastada skleritte gerileme tespit edilirken 3 hastada etanersept tedavisi sonrası da sklerit gelişebildiği bildirilmiştir (29).
RA'lı hastalarda kullanılan anti-TNF olan infliksimab özellikle RA'daki okuler inflamasyon üzerine özellikle refraktor skleriti olan hastalarda etkilidir. Hata ve arkadaşlarının yaptığı çalışmada sistemik ve okuler inflamasyonu olan hastaya siklosporin tedavisi sonrası infliksimab tedavisi başlanmış ve RA ile ilişkili refraktor skleriti ve korneal ülseri olan hastalarda infliksimab uygun tedavi seçeneği olarak görülmüştür. Sonuç olarak infliksimab, topikal veya geleneksel tedavilere cevap vermeyen olgularda bir tedavi seçeneği olarak tercih edilebilir (26).

RA'li hastalarda episkleral nodüller de görülür. Genellikle iki taraflı olup, hastalığın aktif döneminde oluşurlar. Nodüller oldukça hassastır ve sistemik steroid tedavisine çok iyi yanıt verirler.

\section{Retinal vaskülit (RV)}

Retinal vaskuler yapıyı tutan görmeyi etkileyen inflamatuvar bir durumdur. Romatoid artriti olan hastaların \%18'inde retinal vaskülit bulunmuştur. RV'de görme bulanıklığı, skotom ve uçuşmalar gibi semptomlar olmakla birlikte asemptomatik de olabilir. Daha nadir olarak renkli görmede değişiklikler, metamorfopsi ve ağrı görülebilir. Oklüziv retinal vaskülitlerde yumuşak eksüdalar, retinal ödem ve intraretinal hemorajiler görülebilir. T1kanıklığın geç dönemlerinde telenjektaziler, mikroanevrizmalar ve iskeminin tetiklediği neovaskülarizasyonlar tespit edilebilir. Ayrıca vitreus içi hemorajiler ve traksiyonel retina dekolmanları gelişebilir. Fundus muayenesinde, retinal vasküler k1lıflanma, vitritis ve bunlara eşlik eden kistoid makula ödemi en sık rastlanan bulgulardır. Hastalığın görmeyi tehdit eden bulgularını, yayılımını, ciddiyetini tanımlamak için fluoresein anjiografi gerekli bir tanı yöntemidir. Retina pigment epitelinin bütünlüğü ve yoğunluğunu, retinal damarların permeabilitesi ve perfüzyonunu, neovaskülarizasyonun varlığı ve optik disk kabarıklığının yayılımını değerlendirmede önemlidir (30).

RV'lerin tedavisinde ana amaç intraoküler inflamasyonu baskılamaktır (31). Tedavide kullanılan 
ana ilaçlar kortikosteroidlerdir. Topikal, perioküler, intravitreal veya sistemik olarak uygulanabilir. Topikal kortikosteroidler ön kameraya iyi penetre olurken, perioküler kortikosteroidler intermediyer üveit ve maküler ödem tedavisinde etkilidir. RV'de oral kortikosteroidlerle de tedaviye başlanabilir. Başlangıç dozu $1 \mathrm{mg} / \mathrm{kg} /$ gündür ve takiplerde doz kademeli olarak azaltılarak kesilir. Genellikle klinik düzelme tedavinin başlamasından 3-4 hafta sonra görülmeye başlar (32).

RV kortikosteroid tedavisi ile kontrol altına alınamaz veya kortikosteroidler sistemik yan etkilerinden dolayı kullanılamazsa sistemik immunsüpresif ilaçlar tercih edilebilir. $\mathrm{Bu}$ amaçla siklosporin intraoküler inflamasyonu baskılamak için 2,5-5 $\mathrm{mg} / \mathrm{kg} / \mathrm{gün}$ dozunda kullanılır. Ayrica okuler inflamasyonu baskılamak için azatitiopirin, metotreksat, mikofenolat mofetil, takrolimus (FK506), infliksimab gibi diğer immunsüpressif ajanlar kullanılabilir (31,33). RV'e bağlı gelişen iskemik alanlar mevcudiyetinde ise lezyonlara yönelik lazer fotokoagülasyon tedavisi de optimal başarı için uygulanmalıdır.

\section{Toksik retinopati}

RA'lı hastalarda kullanılan hidroksiklorokine bağlı olarak gelişebilmektedir. Günlük hidroksiklorokinin $6,5 \mathrm{mg} /$ gün doz tedavisi aşıldığ 1 durumlarda ortaya çıkar. En erken bulgu santral ve parasantral skotomlara bağlı olarak ortaya çıkan yakın görme alanı defektleri sebebiyle oluşabilecek okumada güçlük şikayetidir, fakat asemptomatik olarak da seyredebilir. Skotomlar genellikle fiksasyon noktasının süperiorunda olup zaman içinde genişler ve sayıları artar. Fiksasyon noktası tutulunca görmede azalma meydana gelir. Fundusta maküler pigmentasyonda düzensizlik ve fovea refleksinde kayıp olur. Santralda pigmentasyon ve parasantral depigmante alan "Bull's eye makulapati" ile sonuçlanır. İlaca devam edilmesi halinde fundus görüntüsünde periferal pigmenter düzensizlik, kemik spekülü formasyonu, vasküler atenuasyon ve optik diskte soluklaşma olur. Fundus floresein anjiografi (FFA) ile makuler pigmentasyon görülebilir. Dolayısıyla ilaç başlamadan önce hastaların santral görme alanı testi ve fundus görüntülenmesi yapılmalıdır. İlaç kullanılırken de 6 ayda bir görme alanı ve fundus görüntülenmesi yapılmalıdır. Amsler kartı denilen ve makula hastalıklarının taranması amacıyla üretilmiş bir kart ile hastalar kendilerini tarayabilir ve bu kart üstündeki çizgilerde kırılma eğilme bükülme veya silinme durumlarında doktora başvurması önerilir.

\section{Brown sendromu}

RA'lı hastalarda süperior oblik kas tendonuyla orbital troklea arasındaki bursanın inflamasyonuna ikincil olarak gelişen nadir bir patolojidir. Gözün adduksiyonunda elevasyon kısitlılığı ve pozitif traksiyon testi ile karakterizedir. İçe yukarı bakış esnasında üst oblik kasın tendonu gevşeyememekte ve tendonun troklear parçasının hareketinde kısıtlılık olmaktadır. Yapılan magnetik rezonans görüntülemede (MRG)'da tendon troklea kompleksinde düzensizlik olduğu gösterilmiştir (34). Tedavide üst oblik tenotomisi, üst oblik tendonunun uzatılması, tendon luksasyonu ve troklea luksasyonu uygulanabilir. $\mathrm{Bu}$ operasyonların sonucunda bazen tam düzelme olurken bazen yetersiz düzelme ve üst oblik felci de meydana gelebir (35).

Romatoid artritli hastalarda nadiren poliklonal gammapatiye sekonder venöz staz retinopatisi, kraniyal sinir felçleri ve genikulokortikal körlük bildirilmiştir.

Sonuç olarak sistemik enflamatuar bir hastalık olan romatoid artritin tanı, takip ve tedavi sürecinde morbiditelerin önlenebilmesi açısından göz bulgularının tanınabilmesi ve gerekli önlemlerin alınmasının hayati öneme sahip olduğu söylenebilir. 


\section{KAYNAKLAR}

1. Gümüşdiş G: Bağ Dokusu Hastalıkları: Romatoid artrit. Gümüşdiş G Doğanavşargil E (eds). Klinik Romatoloji, Deniz Matbaası, İstanbul: 1999; 26979.

2. Reddy SC, Rao UR. Ocular complications of adult rheumatoid arthritis. Rheumatology International. 1996; 16(2): 49-52.

3. Massingale ML, Li X, Vallabhajosyula M, Chen D, Wei Y, Asbell PA. Analysis of inflammatory cytokines in the tears of dry eye patients. Cornea. 2009; 28(9): 1023-7.

4. Foster CS, Yüksel E, Anzaar F, Ekong AS. Dry Eye Syndrome. eMedicine Specialties, Ophthalmology, Lacrimal System. Updated: Nov $15,2010$.

5. Akça BS, Akova YA. Kuru göz tedavisinde güncel tedavi yöntemleri. J Exp Clin Med. 2012; 29: 58-65.

6. Bron AJ. Diagnosis of dry eye. Survey of Ophthalmology. 2001; 45(2): S221-6.

7. Savini G, Prabhawasat P, Kojima T, Grueterich M, Espana E, Goto E. The challenge of dry eye diagnosis. Clin Ophthalmol. 2008; 2(1): 31-5.

8. Liu H, Begley C, Chen M, Bradley A, Bonanno J, McNamara NA, Nelson JD, Simpson T. A link between tear instability and hyperosmolarity in dry eye. Invest Ophthalmology Vis Sci. 2009; 50(8): 3671-9.

9. Dogru M, Tsubota K. New insights into the diagnosis and treatment of dry eye. Ocul Surf. 2004; 2(2): 59-75.

10. Oguz H. Noninvasive tear meniscometry in dry eye patients with Sjogren syndrome. Am J Ophthalmol. 2008; 145(1): 184-5.

11. Schalnus R. Topical nonsteroidal antiinflammatory therapy in ophthalmology. Ophthalmologica. 2003; 217(2): 89-98.
12. Lekhanont K, Park CY, Smith JA, Combs JC, Preechawat P, Suwan-Apichon O, Rangsin R, Chuck RS. Effects of topical anti-inflammatory agents in a botulinum toxin B-induced mouse model of keratoconjunctivitis sicca. J Ocul Pharmacol Ther. 2007; 23(1): 27-34.

13. Marsh P, Pflugfelder SC. Topical nonpreserved methylprednisolone therapy for keratoconjunctivitis sicca in Sjogren syndrome. Ophthalmology. 1999;106(4): 811-6.

14. Tatlıpınar S, Akpek EK. Topical ciclosporin in the treatment of ocular surface disorders. The British Journal of Ophthalmology. 2005; 89(10): 1363-7.

15. Gündüz K, Özdemir O. Topical cyclosporin treatment of keratoconjunctivitis sicca in secondary Sjogren's syndrome. Acta Ophthalmol (Copenh). 1994; 72(4): 438-42.

16. Kunert KS, Tisdale AS, Stern ME, Smith JA, Gipson IK. Analysis of topical cyclosporine treatment of patients with dry eye syndrome: effect on conjunctival lymphocytes. Archives of Ophthalmology. 2000; 118(11): 1489-96.

17. Yılmaz S, Saklamaz A, Demir C, Mermut İ, Şener G, Maden A. Application of utologous serum in dry eye patients. İzmir Atatürk Eğitim Hastanesi T1p Dergisi. 2004; 42: 161-5.

18. Pınarcı EY, Pelit A, Bozkırlı D, Canbolat ET. . Primary Sjögren Syndrome: Case report. Cukurova Medical Journal. 2013; 38 (4): 818-22.

19. Asl1 C, Esen K. Use of Autologous Serum Eye Drops in Ophthalmology Literature: Expanding Indications: Review. Turkiye Klinikleri J Ophthalmol. 2010; 19(3): 161-70

20. Hamideh F, Prete PE. Ophthalmologic manifestations of rheumatic diseases. Seminars in Arthritis and Rheumatism. 2001; 30(4) :217-41.

21. Sims J. Scleritis: presentations, disease associations and management. Postgraduate Medical Journal. 2012; 88(1046): 713-8. 
22. Galor A, Thorne JE. Scleritis and peripheral ulcerative keratitis. Rheumatic Diseases Clinics of North America. 2007; 33(4): 835-54.

23. Sainz de la Maza M, Foster CS, Jabbur NS, Baltatzis S. Ocular characteristics and disease associations in scleritis-associated peripheral keratopathy. Archives of Ophthalmology. 2002; 120(1): 15-9.

24. McCluskey PJ, Watson PG, Lightman S, Haybittle J, Restori M, Branley M. Posterior scleritis: clinical features, systemic associations, and outcome in a large series of patients. Ophthalmology. 1999; 106(12): 2380-6.

25. Okada AA. Immunomodulatory therapy for ocular inflammatory disease: a basic manual and review of the literature. Ocular Immunology and Inflammation. 2005; 13(5): 335-51.

26. Hata M, Nakamura T, Sotozono C, Kumagai K, Kinoshita S, Kurimoto Y. Atypical continuous keratitis in a case of rheumatoid arthritis accompanying severe scleritis. Cornea. 2012; 31(12): 1493-6

27. Jabs DA, Mudun A, Dunn JP, Marsh MJ. Episcleritis and scleritis: clinical features and treatment results. American Journal of Ophthalmology. 2000; 130(4): 469-76.

28. Okhravi N, Odufuwa B, McCluskey P, Lightman S. Scleritis. Survey of Ophthalmology. 2005; 50(4): 351-63.

29. Smith JR, Levinson RD, Holland GN, Jabs DA, Robinson MR, Whitcup SM, et al. Differential efficacy of tumor necrosis factor inhibition in the management of inflammatory eye disease and associated rheumatic disease. Arthritis and Rheumatism. 2001; 45(3): 252-7.

30. Birch MK, Barbosa S, Blumhardt LD, O'Brien C, Harding SP. Retinal venous sheathing and the blood-retinal barrier in multiple sclerosis. Archives of Ophthalmology. 1996; 114(1): 34-9.
31. Walton RC, Ashmore ED. Retinal vasculitis. Current Opinion in Ophthalmology. 2003; 14(6): 413-9.

32. Jabs DA, Rosenbaum JT, Foster CS, Holland GN, Jaffe GJ, Louie JS, Nussenblatt RB, Stiehm ER, Tessler H, Van Gelder RN, Whitcup SM, Yocum D. Guidelines for the use of immunosuppressive drugs in patients with ocular inflammatory disorders: recommendations of an expert panel. American Journal of Ophthalmology. 2000; 130(4): 492-513.

33. Dunn JP. Review of immunosuppressive drug therapy in uveitis. Current Opinion in Ophthalmology. 2004; 15(4): 293-8.

34. Parks MM. Brown's Syndrome. Ed. Duane TD JECoOmas-m, 1th ed. Philadelphia 1988. JBLippincott Co. 1988; chap 20; 4-5.

35. Gerinec A, Slivkova D. Surgery in congenital Brown's syndrome. Cesk Slov Oftalmol. 1997; 53(2): 76-9. 